\title{
Intervention intended to improve public health professionals' self-efficacy in their efforts to detect and manage perinatal depressive symptoms among Thai women: a mixed-methods study
}

\author{
Nitikorn Phoosuwan ${ }^{1,2^{*}}$, Pranee C. Lundberg ${ }^{1}$, Sadiporn Phuthomdee ${ }^{3}$ and Leif Eriksson ${ }^{1}$
}

\begin{abstract}
Background: Targeting perinatal depressive symptoms among women can reduce premature mortality. However, public health professionals (PHPs) in primary healthcare settings often have low self-efficacy for detection and management of perinatal depressive symptoms among women. This mixed-methods study was aimed at developing and evaluating a self-efficacy improvement programme (SIP) intended to increase PHPs' self-efficacy in efforts to detect and manage perinatal depressive symptoms.

Methods: The SIP consisted of 1 day of theory and 4 weeks of practice. Sixty-six PHPs from sub-district health promotion hospitals (primary health care level) in Sakonnakhon, a north-eastern province in Thailand, were randomised into an intervention group $(n=33)$ and a control group $(n=33)$. Twenty-three of the intervention group participants also took part in focus group discussions (FGDs). Multiple linear regression and qualitative content analysis were used to analyse the data.
\end{abstract}

Results: After the SIP, the intervention group participants had higher self-efficacy score than those in the control group ( $p=0.004)$. The FGDs resulted in four categories emerging: Having confidence, Changing knowledge and attitudes, Increasing perception of an important role, and Increasing awareness of performed function.

Conclusions: To enhance the ability of PHPs to detect and manage perinatal depressive symptoms, an intervention programme based on self-efficacy modification is recommended.

Keywords: Depression screening tool, Health professional, Intervention programme, Self-efficacy

\section{Background}

Worldwide, more than $10 \%$ of pregnant women and $21 \%$ of women after childbirth experience depressive symptoms $[1,2]$. Improved mental health of women not only contributes to the third Sustainable Development Goal, reduction of premature mortality [3], but also to the strengthening of mother-child relationships and to the

\footnotetext{
* Correspondence: nitikorn.phoosuwan@pubcare.uu.se

${ }^{1}$ Department of Public Health and Caring Sciences, Faculty of Medicine Uppsala University, BMC, Husargatan 3, Box 564, 75122 Uppsala, Sweden ${ }^{2}$ Department of Community Health, Faculty of Public Health, Kasetsart University Chalermphrakiat Sakonnakhon Province Campus, Sakonnakhon, Thailand

Full list of author information is available at the end of the article
}

reduction of infant growth impairment [4]. Perinatal depressive symptoms can be alleviated by screening the population-at-risk and by correct management [5]. Currently, however, women remain under-screened and have not been well managed for depressive symptoms during the perinatal period (i.e. during pregnancy and after childbirth) in many maternity care settings [4-6]. Moreover, more than $80 \%$ of women with perinatal depressive symptoms do not seek professional assistance due to lack of knowledge [7].

In resource-constrained primary healthcare centres, detection and management of depressive symptoms by trained healthcare providers ( $\mathrm{HCPs}$ ) targeting women 
during the perinatal period can reduce the number of women with symptoms of depression [5, 8]. However, several barriers exist for this to take place, e.g. lack of knowledge about perinatal depressive symptoms, how to use screening tools such as the Edinburgh Postnatal Depression Scale (EPDS) and how to refer women for diagnosis and treatment $[9,10]$. Intervention programmes about detection and management of perinatal depressive symptoms targeting HCPs can assist in overcoming these barriers and potentially have long-term impacts on mothers and children, e.g. maternal health and child development $[6,7]$.

In Thailand, primary healthcare centres are named sub-district health promotion hospitals (SHPHs). In an $\mathrm{SHPH}$, there are about four HCPs, i.e. nurses/midwives with a bachelor's degree in nursing and midwifery, public health professionals (PHPs) with a bachelor's degree in public health, and public health assistants with a diploma degree in public health/dental health. HCPs at SHPHs provide health promotion, disease prevention, treatment and rehabilitation. A nurse/midwife mainly provides antenatal care (ANC). Currently, maternal depression screening is performed once during pregnancy by the nurse/midwife using a two-question tool (2Q) [11]. The $2 \mathrm{Q}$ has been developed by Thai experts for depression screening in the general Thai population [12]. However, in order to properly identify perinatal depressive symptoms among women, a specific screening tool should be implemented [13]. Screening for perinatal depressive symptoms is a preventive action, which could be a routine task for a PHP [8]. To achieve this, PHPs need to be trained and supervised in order to increase their self-efficacy when providing mental health promotion and screening [14-16].

The self-efficacy theory by Bandura [17] focuses on efficacy expectations to improve a person's behaviour. The efficacy expectations may be increased by four information sources: performance accomplishment, vicarious experience, verbal persuasion and physiological states. Performance accomplishment is generated when a person has the correct knowledge and attitude; vicarious experience is experience from a person who is successful in a specific job; verbal persuasion comes from suggestions; and physiological states could come from non-verbal actions. The expectations can, for example, be measured by the Generalized Self-Efficacy Scale, which measures goal setting, effort investment, persistence in face of barriers, and recovery from setbacks [18]. Selfefficacy among HCPs is a key factor for successful detection of maternal depression in a community [9]. It can be improved by an appropriate intervention programme [19].

In order to improve self-efficacy among PHPs in detection and management of perinatal depressive symptoms, a self-efficacy improvement programme (SIP) was developed. This study was aimed at developing and evaluating an intervention programme intended to increase PHPs' self-efficacy in efforts to detect and manage perinatal depressive symptoms.

\section{Methods \\ Study design and setting}

This mixed-methods study has quantitative (randomised controlled trial, RCT) and qualitative (explorative) components in order to get a more comprehensive understanding of the self-efficacy of PHPs after participating in an intervention programme [20]. The quantitative method will demonstrate changes of self-efficacy scores of PHPs in their efforts to detect and manage perinatal depressive symptoms during a self-efficacy improvement programme, while the qualitative method will assist in further exploring the process of implementing the intervention programme. The study was conducted in Sakonnakhon, a north-eastern province of Thailand. Sakhonnakhon has eighteen districts, with approximately 300 PHPs working in 168 SHPHs. Annually, there are approximately 13,000 childbirths in this province [21].

\section{Self-efficacy Improvement Programme (SIP)}

The SIP developed by the researchers was based on Bandura's self-efficacy theory $[17,22]$. It contained two parts: (1) 1 day of theory and (2) 4 weeks of practice. See Table 1.

The day of theory was arranged at the Sakhonnakhon Provincial Public Health Office. It included 8 hours of interactive lectures (devoted to the four information sources from the self-efficacy theory [17]), with focus on the knowledge of motivation for and outcome of detection and management of perinatal depressive symptoms. A manual for psychosocial management from the World Health Organisation (WHO) [23] translated by the first author (NP), with guidelines for detection and management of perinatal depressive symptoms constructed by the authors, and a questionnaire for perinatal depressive symptoms were introduced to the participants by three speakers with experience in psychiatric nursing, health education and behavioural science, as well as public health. The questionnaire comprised the Thai-validated EPDS screening tool for women during antenatal and postnatal periods [24-26], psychological well-being questions [27], self-esteem questions [28], and sense of coherence questions [29]. These tools were introduced according to our previous studies of risk factors for perinatal depressive symptoms among women in a north-eastern province of Thailand [24, 25]. The participants were also given material for practice, such as manuals and questionnaire copies.

The four weeks of practice started directly after the day of theory. During the practice, the participants of 
Table 1 Contents of the Self-efficacy Improvement Programme in relation to the four information sources of Bandura's self-efficacy theory $[17,22]$

\begin{tabular}{|c|c|c|}
\hline Information source & Contents & Implementation \\
\hline \multirow[t]{2}{*}{ Performance accomplishment } & $\begin{array}{l}\text { Knowledge about associated factors and screening for } \\
\text { perinatal depressive symptoms among women }\end{array}$ & $\begin{array}{l}\text { One day of theory lectured by a public health expert, } \\
\text { group work by the participants }\end{array}$ \\
\hline & $\begin{array}{l}\text { Outcomes of detection and management of perinatal } \\
\text { depressive symptoms }\end{array}$ & One day of theory lectured by a public health expert \\
\hline \multirow[t]{2}{*}{ Vicarious experience } & $\begin{array}{l}\text { Experience sharing in the perinatal depressive symptom } \\
\text { management: referral system, diagnosis, treatment } \\
\text { options, community engagements }\end{array}$ & $\begin{array}{l}\text { One day of theory lectured by a psychiatric nurse, } \\
\text { panel discussion }\end{array}$ \\
\hline & $\begin{array}{l}\text { Screening and management for perinatal depressive } \\
\text { symptoms among women in the community }\end{array}$ & Four weeks of practice by the participants \\
\hline \multirow[t]{2}{*}{ Verbal persuasion } & $\begin{array}{l}\text { Motivation for detection and management of perinatal } \\
\text { depressive symptoms }\end{array}$ & $\begin{array}{l}\text { One day of theory lectured by an expert in health } \\
\text { education and behavioural science }\end{array}$ \\
\hline & $\begin{array}{l}\text { Supervision of the participants by phone and mobile } \\
\text { applications }\end{array}$ & Four weeks of practice by a public health expert \\
\hline \multirow[t]{3}{*}{ Physiological states } & $\begin{array}{l}\text { Presentation of a manual for psychosocial management } \\
\text { and guidelines for detection and management of } \\
\text { perinatal depressive symptoms }\end{array}$ & One day of theory lectured by a public health expert \\
\hline & $\begin{array}{l}\text { The use of a questionnaire to screen perinatal depressive } \\
\text { symptoms and its associated factors }\end{array}$ & $\begin{array}{l}\text { One day of theory trained by a public health expert } \\
\text { and practiced in pairs by the participants) }\end{array}$ \\
\hline & Supervision of the participants by face-to-face visit & Four weeks of practice by a public health expert \\
\hline
\end{tabular}

the intervention group were asked to practice with at least two women (one pregnant woman and one woman after childbirth) in their community/SHPH according to the manual and guidelines provided during the day of theory. In order to assist the participants, NP supervised each participant once by phone. In addition, all participants were supervised by NP by mobile applications (Facebook and Line), and field visits were arranged for those who needed face-to-face assistance.

\section{Participants}

\section{Quantitative considerations}

The PHPs were selected randomly from SHPHs in six districts in Sakonnakhon [21]. To be eligible, PHPs should work in the selected districts and be willing to participate in the study. The sample size was determined for RCT with continuous variable [30] (power of test = $80 \%$, effect size $=20 \%$, a set of $95 \%$ significance level, standard deviation $(\mathrm{SD})=4.3$, mean difference $=1.1$ and superiority $\operatorname{margi} n=4$ based on the self-efficacy score among PHPs for detection and management of perinatal depressive symptoms from our pilot study in a province near Sakonnakhon). The required number of participants was at least 28 per group. To compensate for a possible $15 \%$ loss in the follow-up, it was decided to include 33 participants per group.

\section{Qualitative considerations}

After the 4 weeks of practice, 23 out of the 33 PHPs in the intervention group participated in four focus group discussions (FGDs): FGD1 $(n=4)$, FGD2 $(n=8)$, FGD3 $(n=6)$ and FGD4 $(n=5)$. Reasons for not participating in the FGDs were other urgent meetings, lack of time and the work situation at their SHPH.

\section{Procedure}

Initially, the research proposal was sent to the Ethics Committee in Sakonnakhon for approval (SWDCPH2017003). The head of Health Promotion Department of Sakhonnakhon Provincial Public Health Office approved the intervention, and the heads of the District Public Health Offices approved the data collection. Thereafter, invitations containing questionnaires and information about the study were distributed to PHPs by ordinary mail in the six selected districts in Sakonnakhon with high annual number of childbirth. The questionnaire was used to collect baseline data (T1), and the information explained details about the study and contained informed consent forms. Before the study, the PHPs were informed in writing about the purpose of the study, that their participation was voluntary, and that they could drop out from the study at any time. In total, 134 PHPs agreed to participate in the study. Out of them, 33 were randomly allocated to the intervention group and 33 to the control group. Sixty-eight PHPs had to be excluded for reasons such as inability to fully participate. The intervention group members participated in the SIP, while those of the control group worked as usual.

To evaluate the differences between the self-efficacy scores before and after the SIP, the participants of the intervention group were asked to complete a questionnaire on four occasions: during baseline (T1), immediately before the day of theory (T2), immediately after the day of theory (T3) and immediately before the FGDs (T4). The participants of the control group were asked 
to complete the questionnaire on two occasions: during baseline (T1) and close to the time of T4.

The FGDs were carried out at the provincial and district public health offices at a convenient date. Each FGD, with participation of the FGD members, NP and PCL, lasted about 2 hours. NP is male with a master degree in public health and experience in qualitative research, while PCL is female with a PhD degree and experience of nursing/midwifery and qualitative research. They had no relation with the participants before the study was conducted. NP acted as a moderator, while PCL took notes and asked additional questions. During the FGDs, the participants were asked to make clarifications when needed. The discussions were tape-recorded and then transcribed verbatim. All transcripts were given codes without name identification. A flow diagram of the study is shown in Fig. 1.

\section{Data collection}

\section{Collection of quantitative data}

The questionnaire contained questions about sociodemographic characteristics and self-efficacy. The sociodemographic part was developed by NP. It comprised the variables age, gender, marital status, education level, experience of mental health training, years working at the SHPH and size of the SHPH. The self-efficacy part originated from the Thai-translated version [31] of the Generalized Self-Efficacy Scale [18]. In order to assess self-efficacy of PHPs in their efforts to detect and manage perinatal depressive symptoms, the content of the scale was adjusted according to recommendations to capture self-efficacy [32]. The questionnaire had ten items, each scoring from one to four. Thus, the total score ranged from 10 to 40, with higher score indicating higher self-efficacy. Three public health experts approved the content of the questionnaire (Content Validity Index: CVI $>0.80$ ). Internal consistency was performed among 30 PHPs who worked in another province of Thailand, with a Cronbach's alpha coefficient of 0.959 .

\section{Collection of qualitative data}

In the FGDs, the participants of the intervention group described their self-efficacy after they had participated in the SIP. An interview guide constructed by the authors was used to guide the FGDs. It had been tested and adjusted in the first FGD, which was included in the qualitative analysis. The questions in the interview guide were open-ended, as shown in Table 2.

\section{Data analyses}

\section{Quantitative analysis}

Descriptive statistical analysis was performed using, e.g., mean and SD. Baseline sociodemographic characteristics and self-efficacy scores were compared between the intervention and control groups using Pearson chi-square, and Fisher's exact and independent sample t- tests.

The main exposure was the SIP, and the outcome was the self-efficacy score at T4. Linear regression assumptions were checked (i.e. linearity, normality, multicolinearity and homoscedascity). Age, gender, marital status and number of years of work at the SHPH were entered to a multivariable linear regression analysis in order to adjust for potential confounding factors influencing the self-efficacy score. Self-efficacy scores at different times were compared for participants of the intervention group and for participants of the control group by use of paired sample t-test. The level of significance was set at 0.05 , and $95 \%$ confidence interval was used.

\section{Qualitative analysis}

The transcripts were checked by NP to ensure their quality, and they were corrected before the analysis began. An inductive qualitative content analysis was performed, including three phases: preparation, organisation and report [33]. In the preparation phase, NP and PCL selected sentences to prevent fragmentation of words. Manifest content was chosen to maintain results as close to the text as possible. The transcripts were read repeatedly to familiarise ourselves with the texts. NP and PCL, both Thais, read the transcripts separately. The organisation phase comprised two processes: open coding and creation of categories. Open coding implied that notes and headings were written in the margins of texts to describe aspects of contents while reading the transcripts. Thereafter, categories were generated from the written notes and headings, and they were grouped considering their similarities and belongings. NP and PCL discussed the categories until agreement was reached. An example of the transcripts was translated into English in order to allow the non-Thai author (LE), who is male with a $\mathrm{PhD}$ degree and experience of primary healthcare nursing, implementation and qualitative research, to be engaged in the process. Final categories were agreed upon and reported to the participants in the FGDs. Quotations were presented in the results section and annotated with an abbreviation (FGD1-4).

\section{Results \\ Quantitative results}

At baseline, self-efficacy scores and sociodemographic characteristics among the participants of the intervention and the control groups were similar, with exception for age, marital status and number of years of work. See Table 3.

Linear regression analyses (crude and adjusted) were performed. The adjusted analysis demonstrated that after the SIP, the participants of the intervention group 


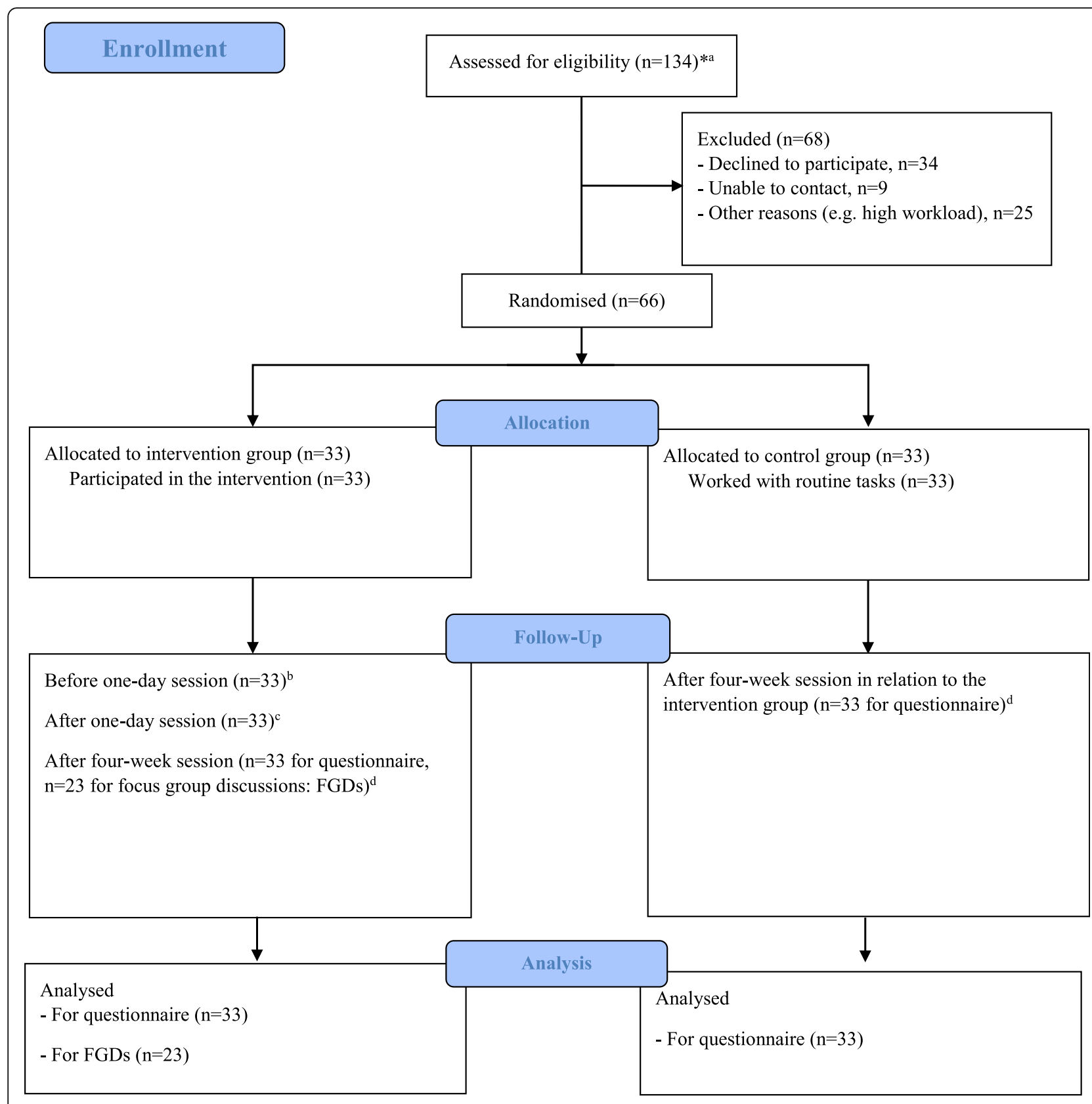

Data from a, b, c and d were labelled as T1, T2, T3 and T4, respectively.

* Public Health Professionals who agreed to participate in the study.

Fig. 1 The flow diagram of the study

had higher self-efficacy score than those in the control group ( $\beta=3.26,95 \%$ CI 1.10-5.42, $p=.004)$. See Table 4.

For the participants of the intervention group, there were significant increases of the scores from T3 to T4, and from $\mathrm{T} 1$ to $\mathrm{T} 4$. However, no significant differences of the self-efficacy scores were detected from T1 to T2 or from T2 to T3 (Fig. 2). The self-efficacy score of the participants of the control group decreased from T1 to T4 $(p=0.002)$.

\section{Qualitative results}

Overall, the participants in FGDs had positive experience from the SIP. The analysis resulted in four categories: Having confidence, Changing knowledge and attitude, 
Table 2 Interview questions used in focus group discussions (FGDs)

1. What are your experiences of meeting women with antenatal depressive symptoms in your community/health centre?

2. Please share your experiences from participating in the one-day theory of the self-efficacy improvement programme (SIP).

3. Please share your experiences from participating in the four-week field practice of the SIP.

4. How has your knowledge, attitude and self-efficacy changed after you participated in the SIP?

5. For evaluation purposes, please give your opinion of the SIP.

6. Is there something we did not discuss that you would like to add to the programme?

Increasing perception of an important role, and Increasing awareness of performed function.

\section{Having confidence}

The participants in FGDs described that PHPs mainly work with communicable disease prevention and control, such as dengue control and surveillance. They disclosed a lack of confidence to work with depressive symptoms, particularly among women during the perinatal period. After the SIP, the participants expressed that having guidelines for screening and management of perinatal depressive symptoms from the intervention programme gave them confidence because they explained theories and how to work in practice. The participants felt that the guidelines were clear. Therefore, they felt it was easy to give women advice and screen for perinatal depressive symptoms. Participants also felt that they were able to explain how to prevent perinatal depressive symptoms when working together with their colleagues (i.e. nurses and other PHPs). They further mentioned that the face-to-face supervision during the 4 weeks of practice was important and increased their confidence.

I gave the guidelines and screening questionnaire to my colleague [a nurse] who is responsible for pregnant women and explained to her how to use the guidelines and how to promote mental health for pregnant women. (FGD1)

The guidelines have clear and appropriate contents for us [PHPS]. I read the guidelines before I worked with women (during pregnancy and after childbirth). I am sure that I can advise women if they are at risk of getting depressed... I think that the supervision has been alright, but it should be longer. (FGD4)

\section{Changing knowledge and attitude}

The participants had limited knowledge about perinatal depressive symptoms before they participated in the SIP. They mentioned that the interactive lectures during the day when the theory was covered provided new knowledge about perinatal depressive symptoms, e.g. how to

Table 3 Socio-demographic characteristics of participants at baseline

\begin{tabular}{|c|c|c|c|}
\hline Characteristics & Intervention group $(n=33)$ & Control group $(n=33)$ & $p$-value \\
\hline \multicolumn{4}{|l|}{ Age (year) } \\
\hline Mean (SD) & $32.21(7.60)$ & $40.12(10.26)$ & $<.01^{* a}$ \\
\hline \multicolumn{3}{|l|}{ Gender, n (\%) } & $.08^{\mathrm{b}}$ \\
\hline Male & $11(33.3)$ & $18(54.5)$ & \\
\hline Female & $22(66.7)$ & $15(45.5)$ & \\
\hline \multicolumn{3}{|l|}{ Marital status, n (\%) } & $.013^{\mathrm{b}}$ \\
\hline Single/widowed & $20(60.6)$ & $10(30.3)$ & \\
\hline Married & $13(39.4)$ & $23(69.7)$ & \\
\hline \multicolumn{3}{|c|}{ Training for mental health, n (\%) } & $0.99^{b}$ \\
\hline Yes & $3(9.1)$ & $4(12.1)$ & \\
\hline No & $30(90.9)$ & $29(87.9)$ & \\
\hline \multicolumn{3}{|c|}{ Size of the Sub-district Health Promotion Hospital, n (\%) } & $.05^{\mathrm{c}}$ \\
\hline Small/medium & $26(78.8)$ & $32(97.0)$ & \\
\hline Large & $7(21.2)$ & $1(3.0)$ & \\
\hline \multicolumn{4}{|c|}{ Number of years of work } \\
\hline Mean (SD) & $7.19(5.38)$ & $11.52(7.03)$ & $.007^{* a}$ \\
\hline \multicolumn{4}{|c|}{ Self-efficacy score at baseline } \\
\hline Mean (SD) & $27.36(3.32)$ & $28.52(5.46)$ & $0.30^{\mathrm{a}}$ \\
\hline
\end{tabular}

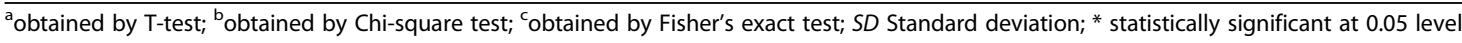


Table 4 Linear regression model for comparison of self-efficacy scores between intervention and control groups after four-week session $(n=66)$

\begin{tabular}{lllll}
\hline & $\begin{array}{l}\text { Crude analysis } \\
\text { coefficient B }(95 \% \mathrm{Cl})\end{array}$ & P-value & $\begin{array}{l}\text { Adjusted analysis } \\
\text { coefficient B }(95 \% \mathrm{Cl})\end{array}$ \\
\hline Intervention & $2.70(0.78,4.62)$ & $.007^{*}$ & $3.26(1.10,5.42)$ & $.004^{*}$ \\
Age & - & - & $0.04(-0.13,0.20)$ & .647 \\
Marital status & - & - & $-1.15(-3.78,1.48)$ & .385 \\
Gender & - & - & $-0.59(-2.83,1.64)$ & .598 \\
Working year & - & - & $0.42(-2.68,3.52)$ & .788 \\
\hline
\end{tabular}

SD Standard deviation, $C l$ Confidence interval

${ }^{*}$ statistically significant at 0.05 level

use standardised tools, and how to prevent such symptoms.

We [PHPs] at SHPHs screened for depressive symptoms using a two-question depression screening tool for the general population because we only had basic knowledge ... Previously, I thought that depressive symptoms occurred among pregnant women but that the symptoms would disappear after childbirth. Now, after the training, I know that depressive symptoms can occur among women, both during pregnancy and after childbirth. (FGD2)

Most of the participants described that they used to focus on the pregnant women's physical condition at the SHPHs, e.g. to perform a physical examination and suggest treatments. However, due to inspiration from the day of theory, perinatal depressive symptoms now get more attention.

Before the SIP, I focused only on the pregnant women's physical health, not on their mental health.
But after the intervention programme, I provide more mental health promotion for the women. (FGD1)

\section{Increasing perception of an important role}

The participants described that PHPs usually worked with mental health tasks guided by government and local policies. However, most PHPs at the SHPHs did not know who should be responsible for preventing perinatal depressive symptoms. For instance, when pregnant women came to the SHPHs, some PHPs assisted the nurse/midwife to count the number of ANC visits, while other PHPs checked pregnant women's vital signs. After the SIP, the PHPs understood that their most important task is to screen and manage perinatal depressive symptoms, because women in the communities know and trust them. They experienced that the SIP had benefits and should be offered to all PHPs in the SHPHs. In this way, every PHP could have the same level of knowledge, which also would reduce the workload of other professionals.

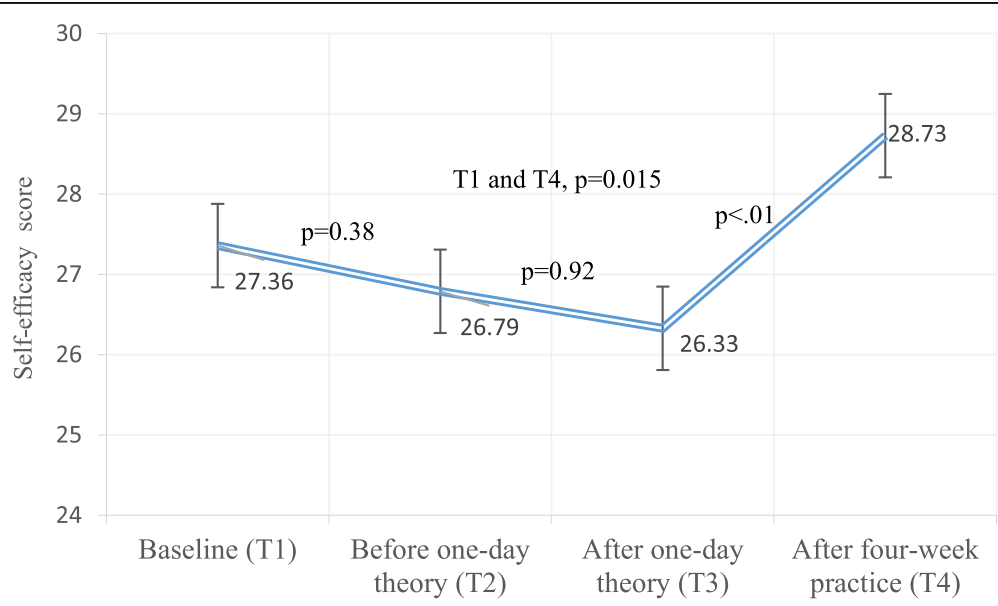

TIME POINTS

Fig. 2 Changes in the self-efficacy scores among participants in the intervention group at baseline (T1), before one-day theory session (T2), after one-day theory session (T3) and after four-week practice session (T4) 
I think that the intervention programme should have more than one day of theory... The programme should be disseminated to PHPs in other SHPHs because all PHPs should know about perinatal depressive symptoms and look for mental health problems among pregnant women. Also, if one PHP is absent, the other PHPs can advise the pregnant woman about mental health instead of just letting her go back home. (FGD1)

\section{Increasing awareness of performed function}

Most of the participants described that providing mental health services during ANC had been perceived as complicated and difficult due to lack of mental health specialists, tools and procedures. They mentioned that the current screening tool for depression (2Q) could not detect perinatal depressive symptom cases properly. After the SIP, the participants planned to adapt their tasks by using the internationalised depression screening questionnaire from the SIP as a tool for screening women, both during pregnancy and after childbirth. They also planned to include women with depressive symptoms into the home visit plan for the multidisciplinary team at the SHPHs in order for pregnant women to receive both physical and mental health services.

I suppose that we will use this developed screening questionnaire. It could increase the effectiveness of our work. Also, if screening would be used in all trimesters of pregnancy, I think we could get a better idea of the mental health situation in the community. (FGD1)

If we knew that this woman is at risk during pregnancy or after childbirth, we would plan with the multidisciplinary team to follow-up and provide more specific support to her. (FGD3)

\section{Discussion}

Previous studies indicate that HCPs in government settings have insufficient self-efficacy to provide care in the communities and are in need of more training [14-16]. Self-efficacy can improve work performance [16]. The self-efficacy theory is widely applied to facilitate behavioural modifications [14] and an appropriate intervention programme has the possibility to increase self-efficacy among PHPs in local communities [16]. The present study revealed that self-efficacy of PHPs in their efforts to detect and manage perinatal depressive symptoms was significantly improved after participation in the SIP, an intervention programme containing both theoretical and practical parts. In the SIP, all four information sources from the self-efficacy theory by Bandura [17] were emphasised and the psychosocial management manual from WHO [23] was provided. One day of theory gave the PHPs in the intervention group opportunity to share their experiences with persons who had been successful in perinatal depressive symptom management, while the 4 weeks of practice gave the PHPs vicarious experiences in screening and management of perinatal depressive symptoms, e.g. giving advice to women who were at risk in the community. The participants' selfefficacy for detection and management of depressive symptoms among women increased, which is an important factor to improve the situation for women during the perinatal period $[8,16,24]$. The results demonstrate that the four information sources from the theory by Bandura [17] are key components for improvement of self-efficacy among PHPs.

The self-efficacy scores among the participants in the intervention group were unchanged between baseline (T1) and directly after the theoretical training (T3), but they were significantly increased between T3 and T4 (after the four-week practice). To increase self-efficacy, it seemed necessary for PHPs to practice what they had learned in theory. This is related to the performance accomplishment in Bandura's theory [17]. Previously, it has also been shown that HCPs with experience from patient practice increase their motivation to work on preventive tasks with women [34]. The FGDs revealed that the participants gained confidence in how to detect perinatal depressive symptoms because they had practiced with at least two women. The participants also had confidence in how to manage perinatal depressive symptoms, i.e. to advise women with an EPDS score $\geq 10$ to meet a physician for diagnosis and treatment. This is in line with previous studies showing that training HCPs on how to detect and manage perinatal depressive symptoms can increase HCPs' confidence when working in primary healthcare centres $[9,10,16]$. The participants also highlighted the importance of the supervision visits during the SIP. These visits in the SIP might be viewed as an information source in the self-efficacy theory of Bandura [17]. Others also expressed that site visits are essential in order to promote better behaviour during an intervention programme [35]. Follow-up sessions can improve confidence to provide better care [36] and encourage self-efficacy to manage behaviour in a better way [37]. Individuals who are well informed and motivated are likely to achieve better outcomes [38]. Hence, based on this study and other research, it seems to be important to integrate supervision in the field practice into a self-efficacy modification intervention programme.

PHPs in the intervention group described that their knowledge and attitude had been increased by their participation in the SIP. Knowledge is a source of personal competence and attitude is a belief to provide a specific 
service [39]. Correct knowledge and attitudes among HCPs are key factors for perinatal mental health actions [9]. Lack of knowledge among HCPs is related to lack of self-efficacy [40], and negative attitude among HCPs may compromise the motivation of depression prevention [39]. Knowledge and attitudes are information sources in the self-efficacy theory [22], and they were both targeted in the SIP. Many intervention programmes focus on improving either knowledge or attitude of HCPs [39, 40]. The current study provides evidence that both knowledge and attitude changed positively by the SIP.

After completion of the SIP, participants in the intervention group perceived that they should screen women for depressive symptoms during the perinatal period using the EPDS because detection and management of depressive symptoms were their responsibilities. This finding is in line with a previous study, suggesting that community health workers are suitable persons to detect and manage perinatal mental health among women [8]. However, the FGD participants also described that HCPs already have a high workload as few HCPs appear in SHPHs, and mental health tasks have not been on their agenda. This situation is not unique for the province of the current study; it has been reported from many settings, particularly in middle-income countries [12, 15]. Nevertheless, universal screening needs to be implemented nationwide and be accessible for all women during the perinatal period $[5,7,13]$. After participation in the SIP, PHPs became more aware of their function at the SHPHs and intended to integrate perinatal mental health tasks into their daily practice. This implied involving women with depressive symptoms in their home visit plan, and increasing accessibility and continuity of care for women with mental health problems in the community [6,9]. Management of women with depression symptoms at a primary care level, should include referral of women with high EPDS scores $(\geq 10)$ for treatment and diagnosis by physicians, which may result in decreased depression severity $[8,24]$.

\section{Strengths and limitation}

A strength of this study was the use of both quantitative and qualitative methods to evaluate the self-efficacy intervention programme [20]. Many factors influenced the perception of self-efficacy among HCPs, including marital status [41], number of years of work and age [16]. These are potential confounders, which have been controlled for in the analysis. This study was a RCT, which help to manage for biases [42]. In addition, by using the qualitative method, the experiences among participants in the intervention programme were explored more in-depth, such as their confidence and application. Trustworthiness was enhanced by having discussions of the results with Thai and non-Thai researchers, by conducting the study with researchers having experiences in public health and nursingmidwifery, by having an interview guide with questions guiding the FGDs, and by having description of contents and methods.

Despite its strengths, the SIP was conducted in a short time period and only with a number of PHPs in a northeastern province of Thailand. This aspect needs to be taken into consideration, e.g. follow-up PHP using screening tool and manual, and field practice during a period longer than 4 weeks. This might result in better improvement of PHPs' self-efficacy scores for detection and management of perinatal depressive symptoms. A more thorough evaluation process [43] might have provided more input on the implementation of the SIP. The circumstance that PHPs in the intervention and control groups did not work at the same SHPHs reduced the risk for contamination between the groups. However, contamination could still happen as PHPs in the intervention and control groups worked in the same districts [44].

\section{Conclusions}

The results of the study indicate that the SIP significantly improved the self-efficacy of PHPs in primary healthcare centres when attempting to detect and manage perinatal depressive symptoms. After participating in the SIP, PHPs in the intervention group reported positive changes in their confidence, knowledge and attitude. The SIP also increased their perception of having an important role and their awareness of performed function at their SHPHs. The intervention programme, supported by supervision, was able to increase the self-efficacy of PHPs in their efforts to detect and manage perinatal depressive symptoms among women. To enhance detection and management of perinatal depressive symptoms by PHPs in primary healthcare centres, a training programme based on self-efficacy modification is recommended.

\footnotetext{
Abbreviations

ANC: Antenatal Care; CVI: Content Validity Index; EPDS: Edinburgh Postnatal Depression Scale; FGD: Focus Group Discussion; HCP: Healthcare Provider; PHP: Public Health Professional; RCT: Randomised Controlled Trial; SHPH: Sub-district Health Promotion Hospital; SIP: Self-efficacy Improvement Programme; WHO: World Health Organisation
}

\section{Acknowledgments}

The authors would like to thank the heads of the provincial and district public health offices in Sakonnakhon for giving us permission to conduct this study, and the public health professionals who participated.

\section{Authors' contributions}

$N P, P C L$ and $L E$ contributed to the conception and design of the study. NP and PCL collected the data. NP, PCL, SP and LE analysed, interpreted, and presented data. All authors were involved in the revision of the manuscript and agreed on its final version. The authors read and approved the final manuscript. 


\section{Funding}

This work was supported by Kasetsart University Chalermphrakiat Sakonnakhon Province Campus, Thailand, and Uppsala University, Sweden. The funding sources had no role in the collection or analysis of the study data. Open access funding provided by Eötvös Loránd University (ELTE).

\section{Availability of data and materials}

The datasets used and/or analysed during the current study are available from the corresponding author on reasonable request.

\section{Ethics approval and consent to participate}

The study was granted ethical approval by the Ethics Committee in Sakonnakhon (SWDCPH2017-003). All participants provided written informed consent ahead of participation.

\section{Consent for publication}

Not applicable

\section{Competing interests}

The authors declare that they have no competing interests.

\section{Author details}

${ }^{1}$ Department of Public Health and Caring Sciences, Faculty of Medicine, Uppsala University, BMC, Husargatan 3, Box 564, 75122 Uppsala, Sweden. ${ }^{2}$ Department of Community Health, Faculty of Public Health, Kasetsart University Chalermphrakiat Sakonnakhon Province Campus, Sakonnakhon, Thailand. ${ }^{3}$ Panyananthaphikkhu Chonprathan Medical Centre, Srinakarinwirot University, Nonthaburi, Thailand.

\section{Received: 12 November 2019 Accepted: 17 February 2020}

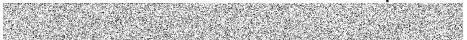

\section{References}

1. Woody CA, Ferrari AJ, Siskind DJ, Whiteford HA, Harris MG. A systematic review and meta-regression of the prevalence and incidence of perinatal depression. J Affect Disord. 2017;219:86-92.

2. Roomruangwong C, Epperson N. Perinatal depression in Asian women: prevalence, associated factors, and cultural aspects. Asian Biomed. 2011;5: 179-93.

3. United Nations: Health - United Nations Sustainable Development. (2017). http://www.un.org/sustainabledevelopment/health/. Accessed 25 Dec 2018.

4. Sha T, Gao X, Chen C, Li L, Cheng G, Wu X, et al. A prospective study of maternal postnatal depressive symptoms with infant-feeding practices in a Chinese birth cohort. BMC Pregnancy Childbirth. 2019:19:388.

5. Stuart-Parrigon K, Stuart S. Perinatal depression: an update and overview. Curr Psychiatry Rep. 2014;16(9):468.

6. Evans MG, Phillippi S, Gee RE. Examining the screening practices of physicians for postpartum depression: implications for improving health outcomes. Womens Health Issues. 2015;25(6):703-10.

7. Fonseca A, Gorayeb R, Canavarro MC. Women's help-seeking behaviours for depressive symptoms during the perinatal period: socio-demographic and clinical correlates and perceived barriers to seeking professional help. Midwifery. 2015;31:1177-85.

8. Niemi M, Kiel S, Allebeck P, Hoan LT. Community-based intervention for depression manangement at the primary care level in Ha Nam Province, Vietnam: a cluster-randomised controlled trial. Tropical Med Int Health. 2016;21(5):654-61.

9. Bayrampour H, Hapsari AP, Pavlovic J. Barriers to addressing perinatal mental health issues in midwifery settings. Midwifery. 2018:59:47-58.

10. Buist A, Condon J, Brooks J, Speelman C, Milgrom J, Hayes B, et al. Acceptability of routine screening for perinatal depression. J Affect Disord. 2006:93:233-7.

11. Ministry of Public Health. Maternal and child health book. Nonthaburi: MoPH Press; 2013.

12. Kongsuk T, Supanya S, Kenbubpha K, Phimtra S, Sukhawaha S, Leejongpermpoon J. Services for depression and suicide in Thailand. WHO South East Asia J Public Health. 2017;6(1):34-8

13. American College of Obstetrics and Gynecology. Screening for perinatal depression. ACOG Comm Opin. 2018;132(5):e208-12.

14. Kamiru HN, Ross MW, Bartholomew LK, McCurdy SA, Kline MW. Effectiveness of a training program to increase the capacity of health care providers to provide HIV/AIDS care and treatment in Swaziland. AIDS Care. 2009;21(11): 1463-70.

15. Saraceno B, van Ommeren M, Batniji R, Cohen A, Gureje O, Mahoney J, et al Barriers to improvement of mental health services in low-income and middle-income countries. Lancet. 2007;370:1164-74.

16. Zamani-Alavijeh F, Araban M, Harandy TF, Bastami F, Almasian M. Sources of health care providers' self-efficacy to deliver health education: a qualitative study. BMC Med Educ. 2019;19:16

17. Bandura A. Self-efficacy: toward a unifying theory of behavioral change. Psychol Rev. 1977;84:191-215.

18. Schwarzer R, Jerusalem M. Generalized self-efficacy scale. In: Weinman J, Wright S, Johnston M, editors. Measures in health psychology: a user's portfolio. Causal and control beliefs. Windsor: Nfer-Nelson; 1995. p. 35-7.

19. Olsen CF, Telenius EW, Engedal K, Bergland A. Increased self-efficacy: the experience of high-intensity exercise of nursing home residents with dementia - a qualitative study. BMC Health Serv Res. 2015;15:379.

20. Creswell JW, Clark VP. Designing and conducting mixed methods research. London: SAGE Publications Ltd; 2000

21. National Statistics Office: Births and deaths by sex: 2006-2015. (2016). http://sakonnk.old.nso.go.th/nso/project/search_option/index. jsp? province $i d=75 \&$ depcode $=01 \&$ gcode $=01 \&$ ccode $=01 \&$ subcode $=01$. Accessed 10 May 2018

22. Bandura A. The explanatory and predictive scope of self-efficacy theory. J Soc Clin Psychol. 1986;4:359-73.

23. World Health Organisation. Thinking Healthy: A manual for psychosocial management of perinatal depression (WHO generic field-trial version 1.0). Geneva: WHO; 2015.

24. Phoosuwan N, Manwong M, Eriksson L, Lundberg PC. Perinatal depressive symptoms among Thai women: a hospital-based longitudinal study. Nurs Health Sci. 2019:1-9. https://doi.org/10.1111/nhs.12669.

25. Phoosuwan N, Eriksson L, Lundberg PC. Antenatal depressive symptoms during late pregnancy among women in a north-eastern province of Thailand: prevalence and associated factors. Asian J Psychiatr. 2018;36:102-7.

26. Pitanupong J, Liabsuetrakul T, Vittayanont A. Validation of the Thai Edinburgh postnatal depression scale for screening postpartum depression. Psychiatry Res. 2007;149:253-9.

27. Nilchaikovit T, Sukying C, Silpakit C. Reliability and validity of the Thai version of the general health questionnaire. J Psychiatric Assoc Thailand. 1996:41:2-17.

28. Wongpakaran T, Wongpakaran N. A comparison of reliability and construct validity between the original and revised versions of the Rosenberg selfesteem scale. Psychiatry Investig. 2012;91:54-8.

29. Antonovsky A. Unraveling the mystery of health: how people manage stress and stay well. San Francisco: Jossey-Bass; 1987.

30. Chow S, Shao J, Wang H. Sample size calculation in clinical research. London: Chapman \& Hall/CRC; 2003.

31. Sukmak V, Sirisoonthon A, Meena P. Validity of the general perceived selfefficacy scale. J Psychiatric Assoc Thailand. 2001;47(1):31-17.

32. Bandura A. Guide for constructing self-efficacy scales. In: Pajares F, Urdan T, editors. Self-efficacy beliefs of adolescents. Greenwich: Information Age Publishing; 2006. p. 307-37.

33. Elo S, Kyngas $\mathrm{H}$. The qualitative content analysis process. J Adv Nurs. 2007; 62(1):107-15.

34. Blair B, Arnow BA, Haas A, Millheiser L. Improving women's sexual health: a quantitative evaluation of an educational intervention for healthcare professionals. Sex Educ. 2013;13(5):535-47.

35. Surr CA, Shoesmith E, Griffiths AW, Kelley R, McDermid J, Fossey J. Exploring the role of external experts in supporting staff to implement psychosocial interventions in care home settings: results from the process evaluation of a randomized controlled trial. BMC Health Serv Res. 2019;19:790.

36. Cheng Y, Cheng L, Chang Y, Li T, Chen C, Huang L. The effectiveness of learning portfolios in learning participation and learners' perceptions of skills and confidence in the mother of preterm infant. Midwifery. 2018;62:86-91.

37. Lundberg PC, Thrakul S. Self-care management of Thai Buddhists and Muslims with type 2 diabetes after an empowerment education program. Nurs Health Sci. 2018;20:402-8.

38. Fisher JD, Fisher WA, Amico KR, Harman JJ. An information-motivationbehavioral skills model of adherence to antiretroviral therapy. Health Psychol. 2006:25:462-73.

39. Kohrt BA, Jordans M, Turner EL, Sikkema KJ, Luitel NP, Rai S, et al. Reducing stigma among healthcare providers to improve mental health services 
(RESHAPE): protocol for a pilot cluster randomized controlled trial of a stigma reduction intervention for training primary healthcare workers in Nepal. Pilot and Feasibility Stud. 2018;4:36.

40. McAllister S, Coxon K, Murrells T, Sandall J. Healthcare professionals attitudes, knowledge and self-efficacy levels regarding the use of selfhypnosis in childbirth: a prospective questionnaire survey. Midwifery. 2017;47:8-14.

41. Odanga SJ, Aloka PJ, Raburu P. Influence of marital status on teachers' selfefficacy in secondary schools of Kisumu County, Kenya. Acad J Interdiscip Stud. 2018;4(3):115-24.

42. Berkman ND, Santaguida L, Viswanathan M, Morton SC. The empirical evidence of bias in trials measuring treatment differences. Rockville: Agency for Healthcare Research and Quality; 2014.

43. Moore GF, Audrey S, Barker M, Bond L, Bonell C, Hardeman W, et al. Process evaluation of complex interventions: Medical Research Council guidance. BMJ. 2015;350:h1258.

44. Delamater PL, Shortridge AM, Messina JP. Regional health care planning: a methodology to cluster facilities using community utilization patterns. BMC Health Serv Res. 2013;13:333.

\section{Publisher's Note}

Springer Nature remains neutral with regard to jurisdictional claims in published maps and institutional affiliations.

Ready to submit your research? Choose BMC and benefit from:

- fast, convenient online submission

- thorough peer review by experienced researchers in your field

- rapid publication on acceptance

- support for research data, including large and complex data types

- gold Open Access which fosters wider collaboration and increased citations

- maximum visibility for your research: over $100 \mathrm{M}$ website views per year

At $\mathrm{BMC}$, research is always in progress.

Learn more biomedcentral.com/submissions 